\title{
THE IMPACT OF PSYCHOLOGICAL WORK ENVIRONMENT TOWARDS EMPLOYEE JOB PERFORMANCE IN HOTEL MANAGEMENT
}

\author{
Ristia Kencana Putri \\ Swiss German University, Tangerang, Indonesia \\ Email: ristia.kencana@gmail.com
}

\author{
Ms. Gemala Garibaldi \\ Swiss German University, Tangerang, Indonesia
}

It is important to take psychological work environment into a study, due to the fact that hotels sometimes do not aware how important is the role of psychological work environment in affecting employee job performance because it is intangible. However, various researches have confirmed that psychological work environment is able to affect positively to employee job performance. Due to this fact, this research aims to study whether the psychological work environment affects employee job performance and to analyze which psychological work environment gives the biggest impact on employee job performance. Simple/linear regression is used to analyze the relationship between psychological work environment and employee job performance. The data used for this quantitative research is collected by questionnaire distributed to a total of 67 staff level employees in a five-star hotel located in Lippo Village. In conclusion, it is confirmed that psychological work environment affects positively to employee job performance, and job attitude gives the biggest impact on employee job performance. The studied company is suggested to improve psychological work environment, particularly job attitude gives the biggest impact.

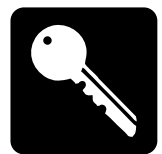

sychological work environment, workload, job attitude, boredom, employee job performance. 


\section{INTRODUCTION}

\section{I.I Background}

he tourism industry is regarded
as the star in the last few years.
Tourism industry makes signif-
icant contributions to the economic development in many countries. The growth of the tourism industry causes lots of hotels around in the city and gives people more choices to stay. Each hotel should compete with others in order to become the first choice of the travelers. Having a good management and doing the supply and demand analysis is a must. But the most important is, hotel should maintain their quality and making it better than before.

As a human based industry, hospitality depends on humans as part of the product, in which, cannot be separated from the service process (Ghazali, 2010). In order to improve the company's performance, management should also improve and maintain their employee

job performance itself. One of the factor that affecting employee job performance is work environment. It is important to have healthy work environment to improve employee job performance. Work environment consists of physical elements around the work area or company facilities, and the psychological factors in the company. Company facilities can be the building of the company, parking garage, office rooms, desks, office equipment, canteen, or even health facilities. The psychological factors in the company is more to the atmosphere that the employees feel in the company, it includes relations between colleagues, employees' attitude, managerial characteristic, and workload given to the employee (Imran et al., 2012). Having a healthy work environment may produce good work environment. Unfortunately, engaging staffs to maintain their good performance is not as easy as falling of a $\log$, besides management sometimes do not give their attention to the environment in the work place. Studies in the context of the hotel sector have shown that working conditions in the hotel sector are poor (Wight \& Pollert, 2006), especially for workload. In this research, the factor that will be studied is psychological factors because not all hotel staff will work with exact same place in a day. They will be more flexible to walk around their area. Psychological work environment also is the key factor in determining an organization's longterm effectiveness (OSHA, 2013). Research by Jain (2014) regarding work environment indicates that lots of hotel employees have problems with the psychological work environment compare to physical factors of work environment. $\mathrm{He}$ also found that workload is the most problematic factors in psychological work environment that may affect employee job performance, followed by job attitude and boredom. From this situation, this research would like to make a study regarding the impact of psychological work environment towards employee job performance to see if they have any correlation and prove if workload affects employee job performance the most.

\section{I.II Research Problem}

1. Hotels in Tangerang have strong competitive atmosphere

2. Hotels with good working environment are rarely to be found. 
3. Human resources teams in hotel industry and top management level sometimes do not recognize how important the quality of work environment is.

4. Human resources teams in hotel industry and top management level do not aware which work environment should be maximized to the company in order to improve employee job performance.

\section{I.III Research Purpose}

The primary purpose of this research is to study whether the psychological work environment gives impact to employee's job performance. The second purpose of this research is to identify whether workload gives the biggest impact to employee job performance.

\section{LITERATURE REVIEW}

\section{II.I Psychological Environment}

According to Briner (2000), psychological factors of work environment is the set of those worker's feelings, thoughts, and behavior. In other words, the psychological environment can be defined as those features of the work environment which are relevant to worker behavior.

The way work environments create psychological environments is less transparent and less direct compared to physical environment. Based on the research from Briner (2000), there are two issues that are relevant. The first one, a great number of aspects of the work environment could potentially affect psychological well-being because the interpretations which workers make of their working conditions have a central role in producing psychological wellbeing. It is not possible to state with certainty that particular aspect of work will necessarily have an impact on well-being as it depends on the way in which work is perceived. The second issue is that it may often be the combination of a number of key work conditions present, which are important for psychological well-being.

Ahealthy psychological work environment is important to ensure job satisfaction and well- being in the workplace. Healthy psychological environment means that there is a balance between the demands made on the employee and the resources and skills that the employee possesses to meet what is requires.

Psychological work environment has several elements which are, workload, job attitude, and boredom. Imran et al. (2014) also stated some elements in psychological environment as followed, relation between colleagues, employees' attitude, boredom, managerial characteristic, and workload given to the employee. But according to a previous study that has been conducted by Jain and Kaur (2014), most employees have problems with workload, job attitude, and boredom.

\section{II.II Employee Job Performance}

Employees in a company are expected to do the best performance in performing their job in a dependable way. They are responsible for successful performance of tasks and duties involved in the job according to the employment contract. Inefficient job performance will bring about a tragedy to the organization as 
associated with lower productivity, profitability and impairment of overall organizational effectiveness (Cooke, 2000; Okoyo \& Ezejiofor, 2013).

According to Moorhead and Griffin (1999) in Hettiararchchi and Jayarathna (2014) job performance is made up of all work-related behavior. And also there is another definition based on Porter and Lawler (1968) in Hettiararchchi and Jayarathna (2014), job performance

is the accomplishment of those tasks that comprise a person's job. It means execution of total set of job related tasks. In conclusion, job performance is activities and behavior that is done by the employee to accomplish company's goals. Based on Drummond (2007), there are some of the reasons employees may not be performing up to standards:

- $\quad$ Poor communication of job duties and performance standards

- Insufficient training, lack of skills

- Over- or under qualification for the job

- Inconsistency or lack of enforcement of policies, procedures, and performance standards

- $\quad$ Lack of support to meet employee's needs for equipment, materials, advice, praise, and so on

- Poor communication within the organization

- $\quad$ Boredom, lack of growth

- $\quad$ Poor working conditions

- Work overload

- $\quad$ Personal problems
- $\quad$ Physical limitations

Campbel et al. (1993) in Sonnentag et al. (2010) stated that performance must be distinguished from effectiveness and from productivity or efficiency. Effectiveness refers to the evaluations of the results of performance. Productivity is the ratio of effectiveness to the cost of attaining the outcome. For example, the ratio of working hours (input) in relation to product assembled (outcome) describes productivity.

Based on Borman and Motowidlo (1993) research in Hettiararchchi and Jayarathna (2014), they suggested that performance can be divided into two parts, task performance and contextual performance. According to Borman and Motowidlo (1997), Motowidlo and Schmit (1999) in Sonnentag et al. (2010) there are three differences between task performance and contextual performance:

1. Contextual performance activities are comparable for almost all jobs, whereas task performance is job specific

2. Task performance is predicted mainly by ability, whereas contextual performance is mainly predicted by motivation and personality

3. Task performance is in-role behavior and part of the formal jobdescription, whereas contextual performance is extra-role behavior and discretionary (i.e. not enforceable), and often not rewarded by formal reward systems or directly or indirectly considered by the management. 


\section{II.III Hypothesis}

Based on the preceding framework of thinking, thehypothesisforthisresearchwill be: H1: Psychological work environment affects employee job performance

H0: Psychological work environment does not affect employee job performance

H2: Workload gives the biggest impact on job performance in hotel industry

H0: Workload does not give the biggest impactonjob performance in hotel industry

\section{METHODOLOGY}

\section{III.I Type Of Research}

The purpose of this research is to analyze the impact of the psychological work environment towards employee job performance in hotel management, therefore this study will be categorized as a causal-explanatory study, a study that is designed to determine cause and effect relationship between variables (Cooper \& Schindler, 2014). This research is quantitative Research. Quantitative research describes the relationship between variables and analyzing numeric data (number) using statistic method (Sekaran \& Bougie, 2014).

\section{III.II Type Of Data}

The combination of primary data and secondary data will be used in this study to conduct the research.

\section{Primary Data}

Primary data refer to information obtained first-hand by the researcher on the variables of interest for the specific purpose of study (Sekaran \& Bougie, 2014). Individuals provide information when interviewed, administered questionnaires, or observed. In this research, primary data will be collected by questionnaires that have been distributed to staff in Hotel Aryaduta Lippo Village.

\section{Secondary Data}

Secondary data refers to information gathered from sources that already exist (Sekaran \& Bougie, 2014). Secondary data can be collected from company records or archives, government publications, industry analyses offered by media, websites, books, articles, and so on. Books, articles, and previous studies will be used to collect secondary data for this research.

\section{III.III Population, Sample, And Sampling Technique}

\section{III.III.I Population}

Thepopulationofthisresearchisallthe 5 star hotel staffs in HotelAryaduta Lippo Village

\section{III.III.II Sample}

The population of Hotel Aryaduta Lippo Village is 200 rank and file employees. Using Slovin's formula and $10 \%$ of margin error, the sample is 67 employees.

\section{III.III.III Sampling Technique}

Sampling technique that used in this research is Stratified random sampling. It is a method of sampling that involves the division of a population into smaller groups known as strata. It will take some 
of the staff in Hotel Aryaduta Lippo Village from different departments. Number of each department that will be taken as sample will be a number proportional to each department's size.

\section{III.IV Analysis Of Data}

The method used for the data analysis is simple/linear regression. Regression is the process of constructing a mathematical model or function that can be used to predict or determine one variable to another variable or other variables (Black, 2008). Linear regression involves two variables-dependent and independent variables. Dependent variable is predicted by independent variable.

\section{RESULTS AND DISCUSSIONS}

\section{IV.I Hypothesis 1}

Simple/linear regression is used to determine one variable to other variable. This method involves two variables, the dependent variable (employee job performance) and the independent variable (psychological work environment). Simple regression can be stated with a linear equation as follow,

$$
\mathbf{Y}=\boldsymbol{\alpha}+\boldsymbol{\beta X}
$$

Y : Employee Job Performance

$\alpha \quad$ : intercept

$\beta \quad$ : regression coefficient

X : Psychological Work Environment

This method of analysis is used to test the first hypothesis of this research. The hypothesis is stated below, Research question: Does psychological work environment affect employee job performance in the hotel industry?

H1: Psychological work environment affects employee job performance

H0: Psychological work environment does not affect employee job performance

The expected result of this test is to reject $\mathrm{H} 0$ and hence $\mathrm{H} 1$ will be accepted. For $\mathrm{H} 0$ to be rejected, the data significance level should be equal to or less than the value of alpha used, which is $10 \%$ or 0,1 . The result of this test is shown in table 4.1

\begin{tabular}{|l|l|l|l|l|l|l|}
\hline $\begin{array}{l}\text { Mod- } \\
\text { el }\end{array}$ & $\begin{array}{l}\text { Sum of } \\
\text { Squares }\end{array}$ & df & $\begin{array}{l}\text { Mean } \\
\text { Square }\end{array}$ & F & Sig. & \\
\hline 1 & Regression & 4.390 & 1 & 4.390 & 28.418 & $.000 \mathrm{~b}$ \\
\hline & Residual & 9.577 & 62 & .154 & & \\
\hline & Total & 13.967 & 63 & & & \\
\hline
\end{tabular}

\section{Source: Data Processing using IBM SPSS Statistics 22}

From the table above, it can be seen that the significance level is 0 and less than the used alpha which 0,1 . The table proves that the $\mathrm{H} 0$ has been rejected and has accepted H1. It represents that psychological work environment has impacts on employee job performance.

Table 4. 2-Regression Coefficient

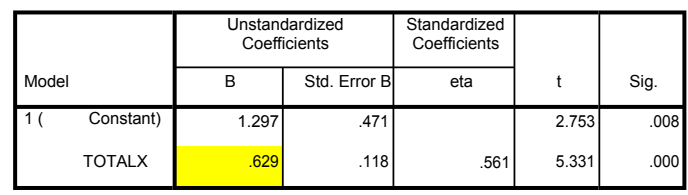

Source: Data Processing using IBM SPSS Statistics 22

The highlighted section in the regression 
coefficient table above indicates that psychological work environment gives impacts on employee job performance positively. Based on simple/linear regression, the equation is stated below.

$\mathrm{Y}=1.297+0.629 \mathrm{X}$

This equation indicates that when variable $\mathrm{X}$ increases 1 causes the increase of variable $Y$ in the amount of 0,629 . These findings are also supported by some previous studies that have been conducted in different countries. Naharuddin and Sadegi,2013; Jayaweera, 2015; Taiwo, 2010; Imran et al., 2012 concluded that bad work conditions contribute to low productivity. Jain and Kaur (2014) found that most of employees are having problems with psychological work environment. They also found that psychological work

environment gives the biggest impact to employee job performance compared to physical work environment. Research has indicated that about $86 \%$ of employee performance problems stay in the work environment of the organization (Sehgal, 2012). A healthy psychological work environment is important to ensure job satisfactionandwell-beingintheworkplace.

\section{IV.II Hypothesis 2}

This research also uses Cross tabulation to find which psychological work environment that gives the biggest impact on employee job performance. Regarding to this purpose, second hypothesis is stated below.

Research Question: Does workload give the biggest impact to employee job performance in the hotel industry?

$\mathrm{H} 2$ : Workload gives the biggest impact on job performance in hotel industry
H0: Workload does not give the biggest impactonjob performance in hotel industry

To test the second hypothesis, cross tabulation of each indicator and dependent variable should be conducted and compared. Indicator with the biggest percentage from the Rsquare value gives the biggest impact on dependent variable (employee job performance).

Table 4. 3-Cross Tabulation Summary

\begin{tabular}{|c|c|c|c|c|c|}
\hline Dimension & PValue & Relationship & R value & $\begin{array}{l}\text { R2 value } \\
\ln (\%)\end{array}$ & Correlation \\
\hline Workload 0 & .005 & Have influence 0 & .408 & 16,6464 W & eak \\
\hline Job Attitude & 0.000 & Have influence & 0.568 & 32,2624 & Adequate \\
\hline Boredom & 0.000 & Have influence 0 & .359 & 12,8881 W eak \\
\hline
\end{tabular}

Source: Data Processing using IBM SPSS 22

If the Rvalue is being compared, workload shows the amount of $16,6464 \%$, Job attitude shows $32,2624 \%$, and boredom shows $12,8881 \%$. These percentages represent their correlation to variable $\mathrm{Y}$ (employee job performance). Job attitude gives the biggest impact to employee job performance. In this case, $\mathrm{H} 2$ is being rejected and it accepts $\mathrm{H} 0$. This result is not in accordance with research conducted by Jain and Kaur (2014) which stated that workload is the most problematic factor in psychological work environment which is affecting employee job performance. Munawaroh et al. (2013) concluded that having too much workload may reduce employee performance. Based on the data analysis, workload does not give the biggest impact to employee job performance, it might be happened

because the questionnaires were given to all departments in the hotel where each department has different responsibilities, 
therefore the amount of work to be done is different from department to department. From the research about individual's perception of time pressure and job performance, Sonnentag and Mojza (2009) concluded that time pressure reduces job performance, not the workload. When employees have to finish their work in limited time, they might not succeed in attaining performance based on standard.

Hotel is an industry that depends on employees as their most important product. It makes teamwork among employees become the most important factor that affect job performance. Job attitude includes how an employee feels towards jobs that are given to $\mathrm{him} /$ her, how an employee behaves when accomplishing their tasks and relationship among colleagues. If they have bad relationship, then it would be difficult to work in team. James Innes (2016) stated that working relationships are very important because they can provide you with an ally, someone who can support your cause and who can help you to resolve problems. The relationship should be two-way streets where employees both give each other advice and support rather than one person doing all the talking and the other expected to receive the advice.

According to Drummond (2007), there are some reasons why employees may not be performing up to standards. The first one is poor communication. When a team has bad relationship among their members, they will not be able to communicate well. If a team does not communicate well, then the members will not perform well as a team. This will associate with the second reason which is lack of skills. The point of team work is they can teach one another and being helpful. When employees have good relationship, they will help each other and also learn new things from others. As a team, employees also have to support one another to give encouragement, advice, and praise. They also can listen to each other's problems and try to solve them. This is important because personal problems become one of the factors that makes employees fail to perform up to standards stated by Drummond (2014).

Hotelogix.com (2014), communication is very important for hospitality industry. Communicating well with guest is the most important skill to give good impression, however having good communication with staff is also important in hospitality industry. Successful communication is a two-way process which requires the management to periodically listen to their staff members' views and ideas (hotelogix. com, 2014). Therefore, management should listen to employees as they are the ones dealing with the guests on a direct, day-to-day basis. Drummond also stated poor working conditions, boredom, and work overload as reasons why employees do not perform up to standards. But mostly, the reasons are associated to job attitude.

As stated Khan et al. (2014) attitude of employees is highly correlated to employee job performance. In the questionnaires that have been distributed to the respondents, the employees mostly have good relationship with colleagues, being part of community in workplace, and often get helped by other colleagues. Hence, having good relationship with colleagues may bring a lot of benefits to employees and will affect their job performance. 


\section{CONCLUSIONS AND RECOMMENDATIONS}

\section{V.I Conclusion}

1. According to the data analysis, this study has accepted $\mathrm{H} 1$ that psychological work environment affects employee job performance. If the psychological work environment increases, employee job performance will also increase. There are also some possibilities of some other factors to influence employee job performance more significantly other than psychological work environment.

2. This research also compares the Rvalue of each indicator from psychological work environment to analyze which one gives the biggest impact on employee job performance. After comparing each Rvalue, the biggest result is job attitude with percentage $32,2624 \%$. This amount represents job attitude as the factor that gives the biggest impact on employee job performance. In this case, the $\mathrm{H} 2$ that states, workload gives the biggest impact on employee job performance in hotel industry, is being rejected.

\section{V.II Recommendations}

\section{V.II.I Recommendations For}

Future Research

Considering some limitations that existed within this research, some recommendation for better study are provided for future researchers who are interested in the same topic.
1. This research is specifically reviewing a current situation in a fivestar hotel with a limited number of respondents which is less than a hundred. The result of this research will not represent a lot of hotels. Therefore, it is recommended to increase the number of sample and collect data from several sources in order to generate more accurate study with generalizable result. It is also recommended to collect data from hotels with different managements. In the execution, longer period of time might also be required.

2. The independent variable that was measured only by three indicators is suggested to be expanded. It is strongly recommended to also do a study on different factors in psychological work environment such as leadership and behavior of supervisors.

3. Due to time limitation, this research only uses questionnaire as the instrument to collect data and only use quantitative research as a method in conducting this study. Mix methods and interview with the respondent are recommended for future research to complete the research with deeper analysis and understanding on the working condition in the company.

\section{V.II.II. Managerial Implications}

From the research that has been conducted, there are some recommendations for the management in the company that has been studied.

a. Improve the psychological workenvironment 
From the data analysis, it represents that there is correlation between psychological work environment and employee job performance. When the psychological work environment increases, employee job performance also increases. To increase employee job performance, company should maintain the workload, build team work culture, and do the cross training.

b. Maintain the workload

Company should manage the workload given to the employees based on their qualification. Having too much workload will cause low productivity and make employees do not perform up to standards. Having too little workload will cause boredom and they will not be challenged by the task they have done. Employees will not experience growth in the company and it causes high employee turnover. Employees also being encouraged to manage their work. Making notes and time frame for the work to be done will be effective to manage the workload given to the employees.

\section{c. Team work}

Company should build the team work culture in order to help the employees have willingness to help each other, not to compete. In the questionnaire that have been distributed to the respondents, some of the employees said that they rarely get helps from their colleagues. Company also has to create the culture of motivating. Giving support, help, and praise will also increase employee job performance because employees will feel they are part of the team.

\section{d. Cross Training}

Having the same routine every day without challenges may cause boredom. Cross training is recommended for the company so the employees get new skills and prevent boredom. By learning new things and having new challenges, employees can also help other department when it is needed. Doing cross training in every 3 months will help employees to reduce boredom and to get new experience.

\section{REFERENCES}

Aguinis, H. \& Cascio, W. F. (1987). Applied Psychology in Human Resource

Management Johns, G. (1946). Organizational Behavior, Understanding and Managing Life at Work

Berry, L.M. (1998). Psychology at Work: an introduction to industrial and organizational psychology

Jankingthong, K. \& Rurkkhum, S. (2012). Factors Affecting Job Performance: A Review of Litterature

Sehgal, S. (2013). Relationship Between Work Environment and Productivity

Taiwo, A. S. (2010). The influence of work environment on workers productivity: A case of selected oil and gas industry in Lagos, Nigeria

Greef, M. D. \& Van den Broek, K. (2004). Quality of the working environment and productivity Research findings and case studies

Dr. Jain, R. \& Kaur, S. (2014). Impact of Work Environment on Job Satisfaction

Munawaroh, A. \& Riantoputra, C. \& Bethesda, S. (2013). Factors Influencing Individual Performance in an Indonesian Government Office

Hettiararchchi \& Jayarathna (2014). The effect of 12 mployee work related attitudes on employee job performance: a study of 
tertiaty and vocational education sector in Sri Lanka

Sekaran, U \& Bougie, R. (2014). Research methods for business sixth edition Gary Dessler (2008). Human Resource Management Eleventh Edition

Karen Eich Drummond (2007). Human Resource Management for The Hospitality Industry

American Institute for Preventive Medicine (2012). Work Stressor Questionnaire.

National Research Center for the Working Environment (2005). Copenhagen Psychosocial Questionnaire.

Koopmans, L., Bernaards, C. M., Hilderbrandt, V. H., Buuren, S. V., Van der Beek, J., De Vet,

H. CW. (2014) Improving the Individual Work Performance Questionnaire using Rasch Analysis.

Briner,R.B.(2000). Relationships between work environments, psychological environments and psychological wellbeing

Sonnentag, S., Volmer, J. \& Spychala, A. (2010). Job Performance

Sarode, A. P. \& Shirsath, M. (2014).
The Factors Affecting Employee Work Environment \& It's Relation with Employee Productivity

Cummings, M. L., Gao, F. \& Thornburg, K. M. (2008) Boredom in the Workplace: A new look at an old problem

Fournier, P.S., Montreuil, S., Bilodeau, C. \& Villa, J. (2011). Exploratory Study to Identify Workload Factors that Have an Impact on Health and Safety.

Shah, S. S. H., Jaffari, A. R., Aziz, J., Ejaz, W., Ul-Haq, I. \& Raza, S. N., (2011). Workload and Performance of Employees

AlBattat, A. R., Som, A. P. M. \& Helalat, A. S. (2013). Overcoming Staff Turnover in the Hospitality Industry using Moley's Model

Msengeti, D. M. \& Obwogi, J. (2015). Effects of Pay and Work Environment on Employee Retention: A Study of Hotel Industry in Mombasa County

Judge, T. A. \& Kammeyer-Mueller, J. D. (2012). Job Attitudes

Dewe, P. J., O’Driscoll, M. P. \& Cooper, C. L. (2012). Theories of Psychological Stress at Work 